\title{
Renal Kolikli Çocuk Hasta Yönetimi: Güncel Medikal ve Cerrahi Tedavi
}

\section{Management of Renal Colic in Pediatric Patients: Current Medical and Surgical Treatment}

\author{
Yasin Bulut1, Akın Soner Amasyalı2, Ferah Sönmez³ \\ ${ }^{1}$ Adnan Menderes Üniversitesi Tıp Fakültesi, Çocuk Sağlığı ve Hastalıkları Anabilim Dalı, Aydın, Türkiye \\ ${ }^{2}$ Adnan Menderes Üniversitesi Tıp Fakültesi, Üroloji Anabilim Dalı, Aydın, Türkiye \\ 3Adnan Menderes Üniversitesi Tıp Fakültesi, Çocuk Nefroloji Bilim Dalı, Aydın, Türkiye
}

\section{ÖZET}

Renal kolik sıkıkla böbrek taş hastalı̆̆ına sekonder gelişen, şiddetli ağrı ile kendini gösteren, acil servislere sık başvuru nedeni olan bir ürolojik acil durumdur. Çocukları ağıı nedeni ile en çok rahatsız eden klinik tablolardan biridir. Ayrıca üriner sistemde tıkanmaya yol açıı̆ında kalıı hasar oluşturabilmektedir. Bu nedenle acil tedavide temel amaç, ağrının etkili şekilde kontrol altına alınması ve üriner tıkanıkıı̆ın böbrek fonksiyon kaybına yol açmadan giderilmesidir. Ayrıca mevcut olma intimali yüksek olan idrar yolu enfeksiyonun tedavi edilmesidir. Pediatrik taş hastalığı klinik görünüm ve tedavi açısından yetişkin hastadan farklııklar göstermektedir. Bu yazıda çocuk acil servisinde renal kolikli çocuk hasta yönetimi ve tedavisi ile ilgili çalışmalar gözden geçirilmiştir. The Journal of Pediatric Research 2014;1(2):62-9

Anahtar Kelimeler: Çocuk, renal kolik, ilaç, cerrahi

\begin{abstract}
Renal colic is an emergent urological problem occurring due to kidney stone disease and characterized by severe pain and is a common cause of admission to emergency departments. Renal colic is one of the most uncomfortable diseases in children due to pain it causes. Also when it leads to blockage in the urinary tract, it may cause permanent renal damage. The main purpose of emergency treatment is to control pain effectively, and resolve urinary obstruction without causing loss of renal function. Treating the potential urinary tract infection is the other goal as well. Pediatric stone disease is different from adults' in terms of clinical presentation and treatment. In this review, studies regarding the management of pediatric patients with renal colic in emergency department are reviewed. The Journal of Pediatric Research 2014;1(2):62-9
\end{abstract}

Key Words: Child, renal colic, drug, surgery 


\section{Giriş}

Renal kolik, sıklıkla böbrek taş hastalığına bağlı olarak gelişen, acil servislerde tanı ve tedavisi yapılan, lomber bölgeden başlayarak anteriordan kasık bölgelerine doğru yayılan kolik vasıflı şiddetli ağrılar ile kendini gösteren bir ürolojik acil durumdur (1). Ağrı tipik olarak kosto-vertebral açıda, künt, sürekli ve kıvrandırıcı bir ağrı şeklinde hissedilir. Bu ağrı sıklıkla kol altından göbeğe veya karın alt kadranlarına doğru yayılabilir. Hastaların birçoğunda böbrek taşı hastalığı veya renal kolik geçirme öyküsü vardır (2). Çocuk hastanelerindeki çocuk sağlığı bilgi sistemine dayalı verilerde hastaneye yatırılan her 685 çocuktan birinin ürolitiyazis olduğu saptanmıştır (3).

Renal kolik ağrısı sıklıkla üriner sistem taşlarından dolayı meydana gelmektedir. Üreter proksimalindeki taşlarda ağrı genellikle kasıklara, distal üreterdekiler de ise testislere ve labialara doğru yayılmaktadır. Nadir de olsa bazen kalça ve dizlere de yayıldığı rapor edilmiştir (4-6). Vakaların \%10'unda gastrointestinal, jinekolojik veya retroperitoneal patolojilere sekonder gelişen ekstrensek üreter tıkanıklığı renal kolik etiyolojisinde rol oynamaktadır. Vakaların sadece \%5'inde ise pyelonefrit ya da üreteropelvik bileşke darlığı gibi üriner sistemin taş dışı patolojileri sonucu meydana gelmektedir (7).

Şiddetli böğür ağrısına, bulantı ve kusma, psikomotor ajitasyon, kosto-vertebral açı hassasiyeti eşlik edebilir. Idrar yolu enfeksiyonun eşlik ettiği taş hastalıklarında ateş gözlenebilir. Üreter alt uç taşı olan hastalarda pollaküri ve ani sıkışma hissi olabilir ve bu hastalarda ağrı, labialara ve skrotuma kadar yayılabilir, bu tablo çocuklarda idrar kaçırma, damla damla idrar yapma ve huzursuzluk şeklinde kliniğe yansır (3).

Böğür ağrısının ayırıcı tanısında böbrek ve üreter taş hastalığı ilk sırada yer alırken, aynı belirti ve bulguları sergileyen pek çok hastalık vardır. Piyelonefrit, üreteropelvik bileşke darlığı gibi üriner sistem hastalıkları ve üretere dıştan bası yapan intestinal, jinekolojik, retroperitoneal ve vasküler patolojiler de aynı tabloyu sergileyebilir. Taşa bağlı akut tıkanıklık sonucu oluşan kolik ağrı devamlıdır, pozisyonla değişmez, ağrı şiddeti artıp azalmaz. Diğer nedenlere bağlı ağrılar böbrek kapsülünün gerilmesi sonucunda oluşur. Bu hastalarda tablo renal kolik kadar gürültülü değildir (3).

Bu derlemede, çocuk olgularda akut renal kolik ve renal koliğe en sık neden olan üriner taş hastalıklarında acil yaklaşım, ağrı kontrolü, genel öneriler, güncel medikal ve cerrahi tedavi seçenekleri gözden geçirilmektedir.

\section{Renal Kolik Fizyopatolojisi}

Üreteral tıkanıklık sonrası intraluminal basınç artışı, mukozada sonlanan sinir uçlarını gererek uyarır ve böylece kolik ağrıya sebep olur. Üreter düz kas lifleri kontrakte olarak üreter lümenine oturan taşı distale doğru itmeye çalışır. Eğer taş, lümeni tamamen dolduracak kadar büyük ise veya üreter darlıklarından birinde kalmışsa, üreter kas lifleri kontrakte olur. Uzamış izotonik kontraksiyonlar sonucu artan laktik asit, yavaş-tip A ve hızlı-tip $C$ sinir liflerini uyarır. Bu uyarı T11-L1 spinal kord seviyesine kadar iletilip, santral sinir sisteminin üst seviyelerine kadar yayılır. Ağrı, üriner sistemle aynı innervasyona sahip gastrointestinal ve genitoüriner sistem organları tarafından da hissedilebilir (8).

Akut üst üriner sistem tıkanıklığı oluşturularak yapılan deneysel çalışmalarda, ilk 1,5 saatte renal pelvis basıncının ve kan akımının arttığı, takip eden 4 saatte de renal pelvis basıncının arttığı, ancak renal kan akımının azaldığı, daha sonra ise her ikisinin de azaldığı gözlenmiştir (9). Prostaglandinlerin sebep olduğu preglomerüler vazodilatasyon ve renal kan akımı artışı, diürezi arttırarak renal pelvis basınç artışına katkıda bulunur. Bu fazda nitrik oksitin preglomerüler vasküler rezistansı azaltarak etki gösterdiği öne sürülmektedir (10). Daha sonra anjiotensin II, tromboksan A2, antidiüretik hormon ve endotelin gibi bir takım mediyatörlerin sorumlu tutulduğu preglomerüler vazokonstrüksiyon gelişir ve intrarenal rezistans artarak renal kan akımında azalma başlar (11).

Glomerüler filtrasyon hızındaki azalma ve idrarın lenfatik ve venöz yolla reabsorbsiyonundaki artış, üreter basıncını düşürür. Glomerüler filtrasyon hızındaki azalma, glomerül kapillerlerindeki net hidrostatik basınç gradiyentinin azalması ve üreter basıncının artması neticesinde artan tübül basıncı sonucu oluşur. Tıkanıklığın kısa sürdüğü veya tam tıkanıklık gelişmediği vakalarda böbrek yetmezliği hemen gelişmez. Bütün bu patolojiler geri döndürülebilir seviyelerde kalabilir (1).

\section{Tanısal Değerlendirme}

\section{Klinik ve Semptomatoloji}

Renal kolik düşünülen hastalarda iyi bir anamnez alınıp detaylı fizik muayene yapıldıktan sonra görüntüleme yöntemlerine başvurulur. Anamnezde günlük aldıkları sıvı miktarı ve çıkardıkları idrar miktarı, beslenme alışkanlıkları, yaşadığı iklim ve coğrafi özellikler, aile öyküsü, hareketsizlik, idrar yolu enfeksiyonu, ilaç alımı, metabolik ve endokrinolojik problemler sorgulanmalıdır. Fizik muayenede, hastanın büyüme-gelişme durumu ve kemik gelişimi önemlidir. Üriner sistem taş hastalığı bulunan çocukların \%15-\%20 'si asemptomatiktir ve başka amaçla yapılan görüntüleme sonucu rastlantısal olarak taş saptanır. Semptomatik olanlarda ise en sık şikayet böğür-karın ağrısıdır (\%50-\%75). Klinik yaşa bağımlı olma eğilimindedir. Ağrı, adölesanlarda \%60, okul çağında \%40, beş yaş altı çocuklarda ise \%20 oranındadır (12). Çok küçük çocuklarda irritabilite, kusma gibi nonspesifik semptomlar yaygındır. Ağrı oranındaki bu farkın nedeni çocuğun kendini ifade edebilme yeteneği ve taşın lokalizasyonudur. Küçük çocuklarda böbrek taşı, büyük çocuklarda ise üreter taşı (\%69-\%82) daha sık görülür. Tipik renal kolik ağrısı böğürde sebat eden ve kasığa uzanan bir ağrıdır. Üreter üst uç taşlarında ağrı aynı taraf testisine yayılabilir. Sağ üreter taşları apandisit, sol üreter taşları ise divetikülit ile karışabilir. Taşlar mesaneye yaklaştıkça irritatif işeme semptomları gelişir. Vakaların birçoğunda mikroskopik hematüri, bulantı ve kusma tabloya eklenir. Erişkinlerde yapılan klinik bir skorlama sistemi, 12 saatten kısa süren 
abdominal veya lomber ağrı, kosto-vertebral açı hassasiyeti ve hematürinin renal koliğin en önemli bulguları olduğunu göstermiştir (13). Erişkinlerde gros hematüri ön planda iken çocuk hastalarda daha az sıklıkta görülür. Çocuklarda mikroskobik hematüri tek gösterge olabilir. Pediatrik vaka serilerinde hematüri, ürolitiyazisli çocuklarda \%30-\%55 arasında klinik bir semptom olarak görülmüştür $(14,15)$.

Üriner taşların tekrar oluşma riski yüksektir. Bu nedenle, bir kez taş oluşturmuş tüm çocuklarda detaylı metabolik inceleme gerekir.

Laboratuvar değerlendirmesinde idrar analizi, idrar kültürü, 24 saatlik idrar ve kanda elektrolit ve iyon düzeyleri ve taş analizi çok önemlidir. Idrar analizinin detaylı ve dikkatli yapılması önemlidir; özellikle idrar $\mathrm{pH}^{\prime} ı$, dansitesi, mikroskobisi ve iyon düzeyi araştırımalıdır. Idrar $\mathrm{pH}^{\prime} ı$ ve kristal içeriği mevcut taşın tipi konusunda önemli ipucu verir. Metabolik değerlendirmede, kanda kalsiyum, kreatinin, ürik asit, fosfor, sodyum, potasyum, bikarbonat ve magnezyum düzeyleri belirlenmelidir. Yirmi dört saatlik idrar örneklerinde volüm, $\mathrm{pH}$, kalsiyum, kreatinin, ürik asit, fosfor, sitrat, okzalat, sodyum, potasyum ve magnezyum ölçümleri yapılmalıdır. Yirmi dört saatlik idrarda kalsiyumun (Ca) $4 \mathrm{mg} / \mathrm{kg}^{\prime} ı$ üzerinde olması hiperkalsiüri olarak tanımlanmıştır (16-18). Ancak, özellikle küçük çocuklarda 24 saatlik idrar toplama güçlükleri nedeniyle, uygulamada spot idrar kalsiyum kreatinin ( $\mathrm{Kr}$ ) ölçümü ile belirlenen $\mathrm{Ca} / \mathrm{Kr}$ oranı günlük uygulamada hiperkalsiüri tanısında kullanımaktadır $(19,20)$. Bu yöntem 24 saatlik idrar kalsiyum atılımı ile değerlendirildiğinde iyi bir ilişki gösterdiği bildirilmiştir (19-25). Hiperkalsiüri tanısı için kesin bir üst sınır değer saptanamamıştır. Genellikle, spot idrar $\mathrm{Ca} / \mathrm{Kr}$ (mg/ mg) oranı 0,21 ve üzeri değerlerde hiperkalsiüri olarak kabul edilmektedir $(16,18)$. Son yıllarda yapılmış bazı çalışmalarda, idrar $\mathrm{Ca} / \mathrm{Kr}$ oranı için yaş ve coğrafik bölgeye göre 0,09 ile 0,37 arasında değişen sonuçlar bildirilmiştir (18-20,1925). Hiperkalsiüri saptanan çocuklarda, hiperparatiroidizm, renal tubuler asidoz ve hiperkalsemiyi dışlamak için serum paratiroid hormon, kalsiyum, fosfor, bikarbonat ve potasyum düzeylerine bakılmalıdır (26).

Ürolitiyazise enfeksiyon eşlik edebileceğinden mutlaka idrar kültürü alınmalıdır. Ülkemizde bildirilen bir çalışmada pediatrik taş hastalığı olgularında hematüri oranı \%43,6, lökositüri oranı \%46 olarak bulunmuştur (27). Bu çalışmada dikkatimizi çeken önemli bir durum lökosit deşarjının diğer çalışmalara oranla yüksek olmasıdır.

\section{Radyolojik Görüntüleme}

Ilk görüntüleme yöntemi olarak ultrasonografi (USG) kullanılmalıdır. Invaziv olmayan, hızlı ve kolay uygulanıp, tekrarlanabilen, taşınabilen ve nispeten ucuz bir tekniktir. Ayrıca iyonizan radyasyon ve kontrast madde uygulanmaması da çocuk ve düşük renal fonksiyonlu hastaların görüntülenmesinde kullanılmasına imkan sağlar $(28,29)$. Radyografinin ortaya çıkaramadığı non opak taşları tespit etmede ayrıca hidronefroz ve yapısal anomalilerin saptanmasında oldukça faydalıdır. USG birçok özelliğinden dolayı renal kolikli hastaların ilk değerlendirilmesinde ve takibinde kullanılan ideal bir yöntemdir (29).
Direkt üriner sistem grafilerinin (DÜSG), üreter taşlarına bağlı gelişen renal koliklerin tanısında sınırlı sensitivite (\%45\%58) ve spesifitesi (\%60-\%77) vardır. Non-opak ürik asit ve ksantin taşları, küçük ve kemik üzerine süperpoze olan taşları göstermekte yetersizdir. Bu nedenle renal koliklerin tanısında tek başına güvenle kullanılan bir yöntem değildir (30).

Kontrastsız bilgisayarlı tomografinin (BT) ise indinavir taşı hariç bütün taş tiplerinde, taşı direk görüntülemesi ve taşa bağlı oluşan hidronefroz, hidroüreter, nefromegali gibi bulguları göstermesi gibi üstünlükleri vardır (3). Çok küçük ve non-opak taşları dahi saptayabilir. Bundan dolayı böbrek taş hastalığı için en doğru ve güvenilir yöntemlerden biri olmaktadır (duyarlılı̆ı \%97, özgüllüğü \%96) (29-33). BT'nin dezavantajı yüksek oranda radyasyona maruz kalınmasıdır. Bununla beraber radyasyon dozu, çocuğun boy ve ağırlığı göz önüne alınarak yeterli görüntü kalitesini bozmadan da ayarlama yapılarak azaltılabilir $(34,35)$. BT renal kolik ve böbrek patolojilerinde ilk seçenek olmamakla birlikte saptanamayan çok küçük non opak taşlarda etkili ve güvenli radyasyon dozlarında kullanılabilir.

Intravenöz pyelografi (IVP) çocuklarda nadir kullanılır. Son yıllarda diğer non-invaziv görüntüleme yöntemlerinin gelişimiyle, renal kolikli hastaların teşhisinde primer tanı yöntemi olarak tercih edilmemektedir. Perkütan, endoüreteral veya açık cerrahi işlemler öncesi üriner sistemin ayrıntılı anatomik görüntülenmesini sağlar. Ayrıca üroepitelyal tümör şüphesinde, renal kolik atağı geçiren ve taş saptanamayan diabetik hastalarda papiller nekroz şüphesinde fayda sağlar (36).

Manyetik rezonans görüntüleme (MRG), iyonizan radyasyon ve kontrast madde kullanılmadığı için üriner sistem taş hastalığı ve tıkanıklık teşhisinde IVP ve BT'ye alternatif bir yöntemdir. T2 sekanslı görüntüler özellikle üreter taşları ve tıkanıklık tanısında kullanıır (37). MR Ürografi, yalnızca hidronefrozu göstermeyip, IVP gibi renal fonksiyonlar hakkında da bilgi vermektedir. Renal kolikten şüphelenilen atipik semptomları olan çocuklarda tercih edilebilir (1).

Özetle, tanısal yöntemler merkezden merkeze farklılıklar gösterse de, daha önce geçirilmiş böbrek taşı hastalığı veya renal kolik öyküsü olanlarda incelemeye USG, DÜSG ile başlanmalıdır. Böyle bir öyküsü olmayan veya atipik şikayetleri olanlarda ise USG ve DÜSG sonrasında kontrastsız BT, cerrahi veya endoskopik işlem öncesi IVP, doppler USG ve bazı özel durumlarda MRG ve MR Ürografi görüntüleme yapılmalıdır (1).

\section{Renal Kolik Tedavisi}

Pediatrik taş hastalığında 3 temel tedavi aşaması mevcuttur. Birincisi, konservatif, medikal ve metabolik tedavidir. Ikincisi acil tedavi yaklaşımıdır. Üçüncüsü ise definitif girişimsel tedavidir. Girişimsel tedavide, endikasyonuna göre açık taş cerrahisi veya daha az sıklıkla ESWL, URS, ve PNL'den oluşan minimal invazif cerrahi uygulanır (38).

Renal kolik tablosunda ise akut epizot (renal kolik, tıkanıklık ve enfeksiyon) ile mücadele edilmeli ve tekrarlayan hastalığın önlenmesi planlanmalıdır.

Akut epizot tedavisinde temel olarak ağrının etkili şekilde giderilip kontrol altına alınması ve üriner obtrüksiyonun renal fonksiyon kaybına yol açmadan giderilmesi amaçlanmalıdır. 
Özellikle bilateral üriner tıkanıklıkla ve anüriye yol açan taşlar ise acil dekompresyon gerektirmektedir (1). Ayrıca tüm üriner taş hastalıklarında, ilk genel öneri bol sıvı alımıdır. Bol sıvı yüküyle, idrar yapımı artmakta, idrardaki çözünmeyen konsantrasyon ve süper satürasyon azaltılabilmektedir. Ağrısı hafif düzeyde olan hastalar oral analjezik ve hidrasyon ile ayaktan tedavi edilebilirken şiddetli ağrısı, bulantı ve kusması olan, idrar çıkımında azalma olan tek böbrekli, enfeksiyon şüphesi olan olgular acilen hastaneye yatırımalıdır.

\section{Akut Medikal Tedavi}

Geçmiște renal kolik tedavisinde ilk seçenek ajanlar morfin ve pethidin olmasına karşın, 1970'lerden itibaren etkinliği kanıtlanmış ajanlar olarak parenteral Nonsteroid antiinflamatuar (NSAI) ilaçlar kullanılmaya başlanmışır. NSAI ilaçlar, opiatlar gibi konstipasyon, solunum depresyonu, mental değişiklikler ve bağımlılık gibi yan etkilerinin olmaması nedeniyle daha fazla tercih edilen ajanlar olmuşlardır (39).

NSAI ilaçlar, prostaglandinlerin etkilerini bloke ederek, afferent arteriolar vazodilatasyon, diürez ve pelvik basınç artışını engellerler. Lokal ödemi azaltıp, inflamasyonu azaltır ve üreter düz kası uyarılmasını engelleyerek peristaltizmi ve üreterik basınç artışını önlerler. NSAI ilaçlar renal kolikte ağrıyı kesmelerinin yanında, renal kan akımını azaltarak böbreğin tıkanıkıka verdiği otoregülatuar cevabı tersine çevirirler (39). Bu amaçla günümüzde en çok kullanılan ilaç grubu NSAl ilaçlardır. Bunların içerisinde en çok tercih edileni çocuk hastarda da kullanılabilen diklofenak sodyumdur ve oral, rektal ve intramusküler yol ile uygulanmaktadır. Daha az kullanılanı ise indomethazindir (40-42). Geçirilmiș böbrek hastalığı olan, renal fonksiyonları bozuk hastalarda NSAl ilaç kullanımı böbrek yetmezliğine yol açabilir (43). Ayrıca NSAl ilaçların ciddi gastrointestinal yan etkileri mevcuttur.

2013 Avrupa Üroloji Birliği Kılavuzu'nda NSAl ilaçların renal kolikte ilk seçenek olduğu ve yeterli ağrı kontrolü sağladığı belirtilmiştir (Tablo I) (44). Ayrıca akut ağrı tedavisi için parenteral formları önerilmektedir. Opiat ilaçlardan özellikle pethidine bağlı kusmanın NSAI ilaçlarla karşılaştııılığında daha fazla olduğu saptanmıştır $(45,46)$. Kılavuzda belirtilen bir çift kör plasebo kontrollü çalışmada ilk 7 gün boyunca NSAI ilaçlar ile tedavi edilen hastalarda taşa bağlı tekrarlayan renal kolik ataklarının daha az görüldüğü bildirilmiștir (47).
Alfa 1-adrenerjik reseptörlerin özellikle de alfa 1D alt grubunun detrusor relaksasyonu ve üreter $1 / 3$ distal ucunun spazmından sorumlu olduğu saptanmıştır. Bu tedavi üreter alt uç taşlarında NSAI ilaçlara adjuvan tedavi olarak kullanılmaktadır. Alfa adrenerjik blokör tedavisi ile amaç üreter distal ucunun spazmını çözerek dilatasyonunu sağlamak ve bu şekilde hem ağrıyı kesmek hem de distal üretral taşların spontan pasajını sağlamaktır (48-50). Çapı $<5 \mathrm{~mm}$ olan taşların büyük çoğunluğu kendiliğinden düşebilir. Hidrasyon, idrar akımını arttııı ve taşın düşme intimalini yükseltir (51).

Erişkinlerde çeşitli ilaçlar üreter taşı geçiş oranını artıırmak için kullanımaktadır fakat çocuklarda bu ajanların kullanımı ile ilgili veriler sınırıdır. Distal üreter taşı olan çocuklarda yapılan çalışmada doksazosin ve ibuprofen karşısştııımış, taş geçişi açısından fark bulunmamıştır (52).

Akut renal kolik medikal tedavisinde opiatlar ve NSAI ilaçlar dışında parasetamol, metamizol sodyum ve alfa blokörler de kullanılabilmektedir. Ilaç tedavisi yanında sıcak uygulamalarının da ağrının geçmesine ilave katkısı vardır $(48,53)$.

\section{Cerrahi Tedavi}

Teknolojik ilerleme ile birlikte taş tedavisi açık cerrahiden daha az invaziv olan endoskopik girişimlere doğru kaymaktadır. Tedavi kararı taşın sayısı, hacmi, lokalizasyonu, muhteviyatı ve üriner sistem anatomisine göre değişebilmektedir (Tablo II) (54).

Günümüzde birçok pediatrik taş hastası Ekstrakorporeal şok dalga tedavisi (ESWL) ile tedavi edilebilmektedir. Mesane ve üreter taşlarında endoskopik tedavi rahatlıkla yapılmaktadır. Aynı zamanda çocuklarda böbrek taşlarında perkütan cerrahi uygulanabilmektedir. Sadece çocuk hastaların az bir kısmında açık cerrahiye intiyaç duyulmaktadır.

Ekstrakorporeal Şok Dalga Tedavisi (Extracorporeal shock wave lithotripsy, ESWL)

Düşük morbidite ve ciddi komplikasyonlarının olmayışı böbrek taşlarında ESWL'nin altın standart tedavi olarak kabul edilmesine neden olmuştur (55). Ortalama şok dalga sayısı 1800-2000 (gerekirse 4000), ortalama güç 14-21 kV arasında değişmektedir (54). Ultrasonografi ve dijital floroskopinin kullanımı ile radyasyon dozu azalmaktadır. Ayrıca yapılan

\begin{tabular}{|l|l|l|}
\hline \multicolumn{2}{|l|}{ Tablo I. Renal kolikte kullanılan ilaçlar, dozları ve tedaviye yanıta göre devam şekli (44) } & Veriliş yolu \\
\hline İlaç adı & lilaç dozu & IM/P0 \\
\hline Diklofenak sodyum (Kanıt düzeyi 1b) & $2-3 \mathrm{mg} / \mathrm{kg} / \mathrm{gün} 2$ eşit doz & P0 \\
\hline Indometasin & $1-2 \mathrm{mg} / \mathrm{kg} / \mathrm{gün} 2-3$ eşit & P0/ IV \\
\hline Parasetamol & $40-60 \mathrm{mg} / \mathrm{kg} / \mathrm{gün} 4$ eşit & P0 \\
\hline İbuprofen & $20-40 \mathrm{mg} / \mathrm{kg} / \mathrm{gün} 3$ eşit & IV \\
\hline Hidromorfon HCL + atropin sülfat & $0,1-0,2 \mathrm{mg}$ & IV \\
\hline Metamizol & $125-500 \mathrm{mg}$ & P0 \\
\hline Doksazosin & $2-6 \mathrm{mg} / \mathrm{gün}$ & P0 \\
\hline Prazosin & $0,5 \mathrm{mg} / \mathrm{doz}$ başlangıç, 3-16 mg idame & IV \\
\hline Tramadol & $1-2 \mathrm{mg} / \mathrm{kg} / \mathrm{doz} 4-6$ doz & IV \\
\hline Meperidin & $0,6-1,5 \mathrm{mg} / \mathrm{kg} / \mathrm{doz} 4-6$ saatte bir & \\
\hline
\end{tabular}


çalışmalarda çocukların erişkine göre daha az radyasyona maruz kaldığı gösterilmiştir (46-48). Infant döneminde bile olsa teknik ve medikasyonlardaki ilerlemeler anestezi konusundaki endişeleri problem olmaktan çıkarmıştır. On yaş altı çocuklarda anestezi tipi genel veya disosiyatif olabilirken, daha büyüklerde intravenöz sedasyon veya kooperasyonu iyi olanlarda analjezi kontrolü ile yapılabilmektedir (54).

Pediyatrik yaş grubunda ESWL'nin başarı şansı \%58-\%90 arasında değişmektedir (56). Taşsızlık oranı lokalizasyondan bağımsız olarak taş hacmi arttıkça azalmakta, tekrar tedavi intiyacı ise artmaktadır. Buna göre $<1 \mathrm{~cm}, 1-2 \mathrm{~cm},>2 \mathrm{~cm}$ ve toplam taşsızlık oranları sırasıyla \%90, \%80, \%60 ve \%80 olarak rapor edilmiştir (57-63).

Birçok çalışmada taş lokalizasyonunun başarıyı öngörmede önemli bir parametre olduğu vurgulanmıştır. Renal pelvis ve üst üreter taşlarında \%90'a yakın başarı oranı varken izole kaliks taşlarında, özellikle alt kaliks taşlarında bu oran \%50\%62'ye kadar düşmektedir. Distal üreterde ise başarı oranı daha düşük bulunmuştur (64-67).

ESWL öncesi üreteral stent yerleştirilmesi taşsızlık oranını etkilemese de toplam komplikasyon oranı stentsizlerde daha fazla olduğu bulunmuştur. Soliter böbrek veya taş yükünün fazla olduğu durumlarda stent yerleştirilmesi önerilmektedir (54). Özellikle taş yükünün fazla olduğu durumlarda ESWL sonrası taş yolu (Steinstrasse) oluşumu ve üriner tıkanıklık açısından yakın takip edilmelidir. Bunun dışında renal kolik, geçici hidronefroz, dermal ekimoz, üriner sistem enfeksiyon, sepsis ve hemoptizi komplikasyonlar arasında sayılmaktadır $(61,62)$. ESWL öncesi idrarın steril hale getirilmesi enfeksiyon komplikasyonlarını önlemek için şarttır.

\section{Perkütan Nefrolitotomi}

Pediatrik böbrek taşlarında ESWL ilk tercih edilen tedavi şekli olsa da büyük kompleks böbrek taşlarında perkütan nefrolitotomi ( $\mathrm{PCNL}$ ) erişkin hastalardaki gibi aynı operatif teknik ile uygulanabilmektedir. Birçok vakada PCNL monoterapi olabileceği gibi beraberinde ek tedavilerle de birlikte uygulanabilir.

Erişkin boyutlu enstrümanların kullanımı kanama için risk oluşturmaktadır. Ancak küçük kalibreli akses kılıf, nefroskop gibi enstrümanların geliştirilmesiyle minimal morbidite ile operasyonlar yapılabilmektedir. Çocuklarda küçük deri insizyonu, tek basamaklı dilatasyon ve akses kılıf yerleştirilmesi, pediatrik enstrümanların rahat kullanımı ve düşük maliyet avantajları arasında sayılmaktadır (54).

Yapılan güncel bir çalışmada pediatrik taş cerrahisinde ilk tercih olarak 2002-2006 yıllarında ESWL \%90,06, retrograt intrarenal cerrahi (RIRC) \%3,1, PCNL \%6,8 oranında uygulanırken, 2007-2011 yıllarında bu oran sırasıyla \%56,3, \%19,7 ve \%23,8 olarak değişmiştir (68) (Grafik 1). Enstrümanların minyatürize edilmesi ile tercih edilen tedavi modalitesi de endoskopik cerrahiye doğru kaymıştır (68).

Monoterapi olarak PCNL efektif ve güvenli bir prosedür olarak kabul edilmektedir. Tek seansta başarı oranı \%86,9$\% 98,5$ arasında değişmektedir. ESWL veya üreterorenoskopi gibi ek prosedürlerle başarı oranı daha da artmaktadır. Staghorn tipi taşlarda dahi taşsızlık oranın tek seansta \%89'a kadar çıkmaktadır (69-71).

\section{Retrograt İntrarenal Cerrahi (RIRC)}

Küçük boyutlu endoürolojik ekipmanların kullanımının artmasıyla pediatrik üreteral hatta böbrek taşlarının tedavisi endoskopik olarak yapılabilmektedir. Teknik olarak erişkin üreterorenoskopi ile aynı cerrahi prensipler geçerli olup, guide wire eşliğinde direk vizüel olarak işlem yapılmaktadır. Rutin üreterovezikal bileşkenin balon dilatasyonu ve stent yerleştirilmesi ise tartışmalıdır. Hidrodistansiyon daha sık kullanılan ve üreteral dilatasyon için benzer etkiye sahiptir (72).

\begin{tabular}{|c|c|c|c|c|}
\hline Taş boyutu ve lokalizasyonu & $\begin{array}{l}\text { Primer Tedavi } \\
\text { Opsiyonu }\end{array}$ & $\begin{array}{l}\text { Kanit } \\
\text { düzeyi }\end{array}$ & Sekonder tedavi opsiyonu & Yorum \\
\hline Staghorn taşlar & PCNL & $2 B$ & Açık/ESWL & $\begin{array}{l}\text { Birkaç seans gerekebilir. PCNL ESWL ile kombine dilmesi faydalı } \\
\text { olabilir. }\end{array}$ \\
\hline Renal Pelvis $<10 \mathrm{~mm}$ & ESWL & $1 \mathrm{~A}$ & $\mathrm{RIRS/PCNL}$ & \\
\hline Renal Pelvis $10-20 \mathrm{~mm}$ & ESWL & $2 B$ & PCNL/Açık & ESWL ile birkaç seans gerekebilir. \\
\hline Pelvis $>20 \mathrm{~mm}$ & PCNL & $2 B$ & ESWL/Açık & ESWL ile birkaç seans gerekebilir. \\
\hline Alt pol kaliks $<10 \mathrm{~mm}$ & ESWL & $2 B$ & RIRS/PCNL & ESWL ile taş temizlenmesinde anatomik varyasyonlar önemlidir. \\
\hline Alt pol kaliks $>10 \mathrm{~mm}$ & PCNL & $2 B$ & ESWL & ESWL ile taş temizlenmesinde anatomik varyasyonlar önemlidir. \\
\hline Üst üreter taşı & ESWL & $2 B$ & PCNL/URS/Açık & \\
\hline Alt üreter taşı & URS & $1 \mathrm{~A}$ & ESWL/Açık & ESWL ile ek tedavi gereksinimi yüksektir. \\
\hline Mesane taşı & Endoskopik & $2 B$ & & $\begin{array}{l}\text { Büyük taşlarda açık cerrahi daha kolay ve daha az operasyon } \\
\text { süresine sahiptir. }\end{array}$ \\
\hline
\end{tabular}

CNL: Perkutan nefrolitotomi, ESWL: Ekstrakorporeal shock-wave litotripsi, RIRS: Retrograt intrarenal cerrahi, URS: Üreteroskopi 


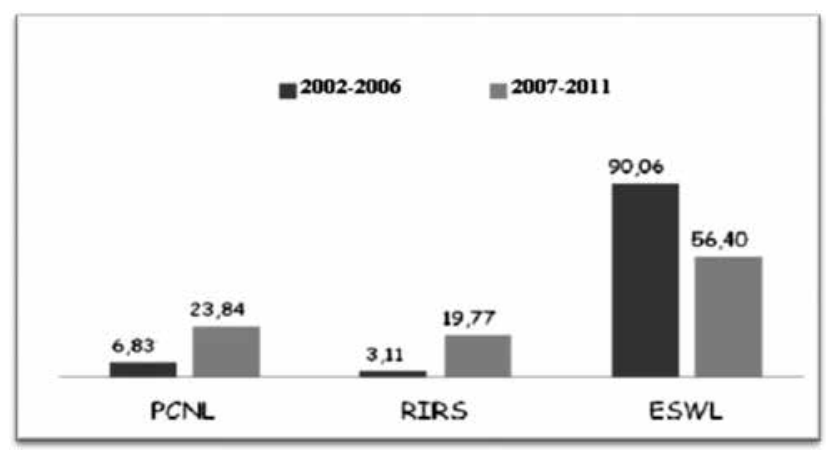

Grafik 1. Yıllara göre ilk tedavi prosedürü yüzde oranları (68) PCNL: Perkütan nefrolitotomi, RIRS: Retrograt intrarenal cerrahi, ESWL: Ekstrakorporeal şok dalga tedavisi

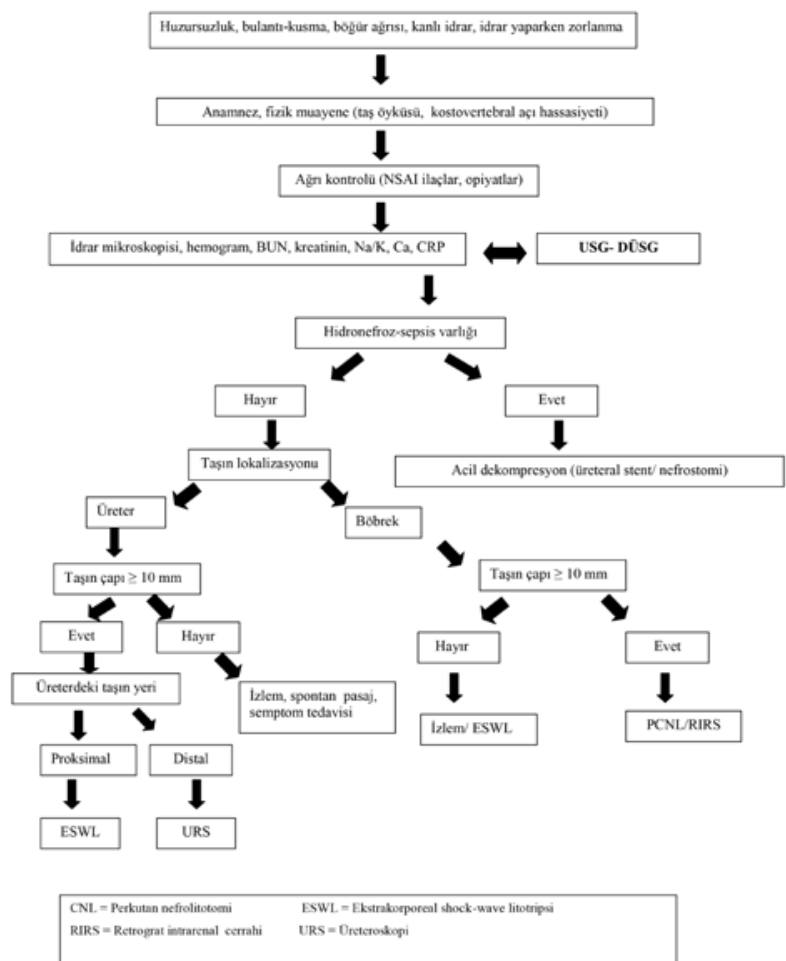

Şekil 1. Renal kolik tablosunda başvuran çocuk hastaya yaklaşım algoritması

Değişik litotripsi yöntemlerinin (ultrasonik, pnömotik, lazer) hepsi güvenli ve efektiftir. Lazer enerji problarının küçük olması, minyatürize enstrümanlarda kullanımının daha kolay ve kullanışlı olmasını sağlamaktadır (73).

Birçok çalışmada, çocuklardaki üreterik taşların endoskopik tedavisinin üreteral striktür veya vezikoüreteral reflü için risk oluşturmadığı rapor edilmiştir. Çok merkezli bir çalışmada semirijit üreterorenoskopi ile üreteral taşların tedavisinde \%90 taşsızık oranı bulunmuştur. Aynı çalışmada çok değişkenli analize göre komplikasyon oranını etkileyen tek faktörün operasyon süresi olduğu gösterilmiştir (74).

Mevcut kılavuzlara göre $<2 \mathrm{~cm}$ ve $>2 \mathrm{~cm}$ böbrek taşları için ilk öneri sırasıyla ESWL ve PCNL olsa da, 2 cm'ye kadar hatta $2 \mathrm{~cm}$ 'nin üzerindeki böbrek taşları için RIRC ilk tercih olmaya başlamıştır. Sepsis ve kanama gibi PCNL komplikasyonlarının RIRC ile daha az görülmesinin yanında Bozkurt ve ark. alt pol taşlarında taşsızlık oranını PCNL ile karşılaştırılabilir $(\% 89,2)$ olduğunu göstermişlerdir (75). Güncel bir çalışmada ise Akman ve ark. taşsızlık oranını RIRC için \%92,8 ve PCNL için \%96,4 olarak rapor etmişlerdir. Aynı çalışmada komplikasyon oranları sırasıyla \%7,1 ve $\% 10,7$ olarak bulunmuştur (76). Retrograt intrarenal cerrahide kullanılan fleksible enstrümanların kullanışı olmasına rağmen, diğer endoürolojik modalitelerle karşılaştırılabilmesi için daha fazla çalışmaya ihtiyaç vardır.

\section{Açık Cerrahi}

Birçok pediatrik taş hastası ESWL veya endoürolojik tekniklerle tedavi edilmesine rağmen, bazı durumlarda açık cerrahi kaçınılmaz olmaktadır. Taş yükünün fazla olduğu çok küçük çocuklarda, konjenital tıkanıklık olan ve beraberinde cerrahi tamir gerektiren vakalar açık operasyon için uygundur. Ayrıca endoskopik prosedüre engel olacak ortopedik deformitesi olan hastalarda da açık operasyon gerekebilmektedir (54).

Yeterli tecrübeye sahip merkezlerde laparoskopik yaklaşım açık cerrahiye alternatif olabilir. Başarısız endoskopik prosedürler sonrası, kompleks renal anatomi (ektopik yada retrorenal kolon), birlikte üreteropelvik bileşke tıkanıklık, kalisiyel divertikül, megaüreter vaya geniş impakte taş varlığı laparoskopik cerrahi için olası endikasyonlardır. Laparoskopi transperitoneal veya retroperitoneal yolla yapılabilmektedir. Ancak bu teknikler rutin terapötik modaliteler arasında değildir (77).

Mesane taşları genellikle endoskopik olarak tedavi edilmektedir. Büyük mesane taşlarında veya anatomik bozukluğa bağlı mesane taşlarında açık cerrahi de yapılabilmektedir $(72,73)$.

\section{Sonuç}

Acil servislere başvuran renal kolikli çocuk hastaların tedavisinde temel olarak ağrının etkili şekilde giderilip kontrol altına alınması ve üriner obtrüksiyonun renal fonksiyon kaybına yol açmadan giderilmesi amaçlanmalıdır. Bu hastaların ağrılarının giderilmesi için uygun ve etkili analjezik seçimi önemlidir. Analjezik olarak öncelikle NSAI ilaçlar tercih edilmeli ve yeterli hidrasyonla hastanın rahatlaması sağlanmalıdır. Üriner tıkanıklık gelişen hastalara acil üroloji konsültasyonu istenmeli, yeterli üriner açıklık sağlanarak akut böbrek yetersizliği gelişimi önlenmelidir. Özellikle soliter böbrekli hastalarda veya bilateral üriner tıkanıklıka ve anüriye yol açan taşlara bağlı renal kolikte acil dekompresyon yapılması sağlanmalıdır (Şekil 1).

Çıkar Çatışması: Yazarlar bu makale ile ilgili olarak herhangi bir çıkar çatışması bildirmemiştir.

\section{Kaynaklar}

1. Müslümanoğlu AY, Tepeler A. Renal kolik tanı ve tedavisi. Marmara Medical Journal 2008; 21: 187-92. 
2. Anderson $K R$, Smith RC. CT for evaluation of renal cholic pain. J Endourol 2001; 15: 25-9.

3. Bush NC, Xu L, Brown BJ, Holzer MS, Gingrich A, Schuler $B$, Tong L, Baker LA. Hospitalizations for pediatric stone disease in United States, 2002-2007. J Urol 2010; 183: 1151-6.

4. Kabalin JN, Walsh PC, Retik AB, Vaughan ED, Wein AJ. Surgical anatomy of the retroperitoneum, kidneys and ureters. In Campbell's Urology, 7th ed. Philadelphia, Saunder, 1998; 49-88.

5. Sadam, Esen A, Çelebi I, Mungan U. Ürogenital sistemin acil yaklaşım gerektiren hastalıkları. In Temel Üroloji (Eds K Anafarta, Y Bedik):963-73. Ankara, Güneş Kitabevi, 1998.

6. Moll J, Peacock IV. Urologic stone disease. In Emergency Medicine: A comprehensive Study Guide, 6th ed (Eds JE Tintinalli JE, GD Kelen, JS Stapczynski). North Carolina, McGraw Hill, 2004: 620-5.

7. Perlmutter A, Miller L, Trimble LA, Marion DN, Vaughan ED Jr, Felsen D. Toradol, an NSAID used for renal colic, decreases renal perfusion and ureteral pressure in a canine model of unilateral ureteral obstruction. J Urol 1993; 149: 926-30.

8. Bihl G, Meyers A. Recurrent renal stone disease: advances in pathogenesis and clinical management. Lancet 2001; 358: $651-6$.

9. Moody TE, Vaughn ED Jr, Gillenwater JY. Relationship between renal blood flow and ureteral pressure during 18 hours of total unilateral uretheral occlusion: implications for changing sites of increased renal resistance. Invest Urol 1975; 13: 246-51.

10. Lanzone JA, Gulmi FA, Chou SY, Mooppan UM, Kim H. Renal hemodynamics in acute unilateral ureteral obstruction: contribution of endothelium-derived relaxing factor. J Urol 1995; 153: 2055-9.

11. Reyes $A A$, Klahr S. Renal function after release of ureteral obstruction: role of endothelin and the renal artery endothelium. Kidney Int 1992; 42: 632-8.

12. Pietrow PK, Pope JC 4th, Adams MC, Shyr Y, Brock JW 3rd. Clinical outcome of pediatric stone disease. J Urol 2002; 167: 670-3.

13. Eskelinen M, Ikonen J, Lipponen P. Usefulness of historytaking, physical examination and diagnostic scoring in acute renal colic. Eur Urol 1998; 34: 467-73.

14. Coward RJ, Peters CJ, Duffy PG, Corry D, Kellett MJ, Choong $S$, van't Hoff WG. Epidemiology of paediatric renal stone disease in the UK. Arch Dis Child 2003; 88: 962-5.

15. Milliner DS, Murphy ME. Urolithiasis in pediatric patients. Mayo Clin Proc 1993; 68: 241-8.

16. Milliner DS. Urolithiasis. In: Avner ED, Harmon WE, Niaudet P, (eds). Pediatric Nephrology. Philadelphia: Lippincott Williams\&Wilkins, 2004: 1094-5.

17. Alon US, Berenbom A. Idiopathic hypercalciuria of childhood: 4-7 years outcome. Pediatr Nephrol 2000; 14: 1011-5.

18. Guignard JP, Santos F. Laboratory investigations. In: Avner ED, Harmon WE, Niaudet P, (eds). Pediatric Nephrology. Philadelphia: Lippincott Williams \&Wilkins, 2004: 403.

19. So NP, Osorio AV, Simon SD, Alon US. Normal urinary calcium /creatinine ratios in African-American and Caucasian children. Pediatr Nephrol 2001; 16: 133-9.

20. Mir S, Serdaroglu E. Quantification of hypercalciuria with the urine calcium osmolality ratio in children. Pediatr Nephrol 2005; 20: 1562-5.

21. Vachvanichsanong P, Lebel L, Moore ES. Urinary calcium excretion in healthy Thai children. Pediatr Nephrol 2000; 14: 847-50.

22. Esbjörner $E$, Jones IL. Urinary calcium excretion in Swedish children. Acta Pediatr 1995; 84: 156-9.
23. Safarinejad MR. Urinary mineral excretion in healthy Iranian children. Pediatr Nephrol 2003; 18: 140-4.

24. Sönmez F, Akçanal B, Altincik A, Yenisey C. Urinary calcium excretion in healthy Turkish children. Int Urol Nephrol 2007; 39: 917-22.

25. Koyun M, Güven AG, Filiz $S$, Akman $S$, Akbas H, Baysal YE, Dedeoglu N. Screening for hypercalciuria in schoolchildren: what should be the criteria for diagnosis?. Pediatr Nephrol 2007; 22: 1297-1301.

26. Önen A: Çocuklarda Üriner Sistem Taş Hastalığı. Önen A (editor): Çocuk Cerrahisi ve Çocuk Ürolojisi Kitabı. Nobel Tıp Kitabevleri, İstanbul, 2006

27. Bozkurt Y, Ece A, Yolbaş I, Sancaktar AA,Kelekçi S, Güneş A, Yel S. Pediatrik ürolitiy azis: 342 hastaya ait verilerin değerlendirilmesi. Düzce Tıp Fakültesi Dergisi 2009; 11: $21-5$.

28. Shokeir AA. Renal colic: pathophysiology, diagnosis and treatment. Eur Urol 2001; 39: 241-9.

29. Patlas M, Farkas A, Fisher D, Zaghal I, Hadas-Halpern I. Ultrasound vs CT for the detection of ureteric stones in patients with renal colic. Br J Radiol 2001; 74: 901-4.

30. Shokeir AA, Abdulmaaboud M. Prospective comparison of nonenhanced helical computerized tomography and Doppler ultrasonography for the diagnosis of renal colic. $J$ Urol 2001; 165: 1082-4.

31. Hamm M, Wawroschek F, Weckermann D, Knöpfle E, Hackel T, Hauser H, Krawczak G, Harzmann R. Unenhanced helical computed tomography in the evaluation of acute flank pain. Eur Urol 2001; 39: 460-5.

32. Meagher T, Sukumar VP, Collingwood J, Crawley T, Schofield $D$, Henson $\mathrm{J}$ et al. Low dose computed tomography in suspected acute renal colic. Clin Radiol 2001; 56: 873-6.

33. Krishna NS, Morrison L, Campbell C. Is spiral computed tomography the imaging modality of choice for renal colic? Postgrad Med J 2001; 77: 124-132.

34. Brenner DJ, Hall EJ. Computed tomography--an increasing source of radiation exposure. N Engl J Med 2007; 357: 2277-84.

35. Karmazyn B, Frush DP, Applegate KE, Maxfield C, Cohen $M D$, Jones RP. CT with a computer-simulated dose reduction technique for detection of pediatric nephroureterolithiasis: comparison of standard and reduced radiation doses. AJR Am J Roentgenol 2009; 192:143-9.

36. Dalla Palma L. What is left of i.v. urography? Eur Radiol 2001; 11: 931-9.

37. Evans HJ, Wollin TA. The management of urinary calculi in pregnancy. Curr Opin Urol 2001; 11: 379-84.

38. Önen A. Çocuklarda üriner sistem taş hastalığı. Turk Arch Ped 2010; 45 Suppl: 104-9.

39. Miralles R, Camí J, Gutierrez J, Torne J, Garces JM, Badenas JM. Diclofenac versus dipyrone in acute renal colic: a double-blind controlled trial. Eur J Clin Pharmacol 1987; 33: 527-8.

40. Al-Waili NS. Intramuscular tenoxicam to treat acute renal colic. Br J Urol 1996; 77: 15-6.

41. Tiselius HG, Ackermann D, Alken P, Buck C, Conort P, Galluci M, Knoll T. Guidelines on urolithiasis 2006.

42. Hollingsworth JM, Rogers MA, Kaufman SR, Bradford TJ, Saint S, Wei JT, Hollenbeck BK. Medical therapy to facilitate urinary stone passage: a meta-analysis. Lancet 2006; 368: 1171-9.

43. Menon M, Resnick, MI. Urinary lithiasis: Etiology, diagnosis and medical management. In Campbell's Urology. Ed. Walsh, Retik, Vaughan and Wein, Eight Edition. Philadelphia, WB Saunders, 2002; 3229-3306.

44. Türk C, Knoll T, Petrik A, Sarica K, Straub M, Seitz C. European Association of Urology 2011 Guidelines on Urolithiasis. 2011;17-20. 
45. Holdgate A, Pollock T. Nonsteroidal anti-inflammatory drugs (NSAIDs) versus opioids for acute renal colic. Cochrane Database Syst Rev 2005; 2: CD004137.

46. Esquena S, Millan Rodriguez F, Sanchez-Martin FM, Rousaud Baron F, Marchant F, Villavicencio Mavrich $H$. Renal colic: revision of literature and scientific evidence. Actas Urol Esp 2006; 30: 268-80.

47. Laerum E, Ommundsen OE, Grønseth JE, Christiansen A, Fagertun HE. Intramuscular diclofenac versus intravenous indomethacin in the treatment of acute renal colic. Eur Urol 1996; 30: 358-62.

48. Lipkin M, Shah O. The use of alpha-blockers for the treatment of nephrolithiasis. Rev Urol 2006; 8 Suppl 4: S35-42.

49. Malin JM Jr, Deane RF, Boyarsky S. Characterisation of adrenergic receptors in human ureter. $\mathrm{Br} \mathrm{J}$ Urol 1970; 42: 171-4.

50. Yılmaz E, Batislam E, Basar MM, Tuglu D, Ferhat M, Basar $\mathrm{H}$. The comparison and efficacy of 3 different alpha1adrenergic blockers for distal ureteral stones. J Urol 2005; 173: 2010-2012.

51. Kalorin CM, Zabinski A, Okpareke I, White M, Kogan BA. Pediatric urinary stone disease--does age matter? J Urol 2009; 181: 2267-71.

52. Aydogdu O, Burgu B, Gucuk A, Suer E, Soygur T. Effectiveness of doxazosin in treatment of distal ureteral stones in children. J Urol 2009; 182: 2880-4.

53. Ay MO, Avcı A, Acehan $S$, Gülen M, Içme F, Sebe A. Acil Serviste Renal Kolikli Hasta Yönetimi. Management of Patients with Renal Colic in Emergency Department. Arşiv Kaynak Tarama Dergisi. Archives Medical Review Journal 2014; 23: 345-61.

54. Tekgül S, Riedmiller H, Dogan HS, Hoebeke P, Kocvara R, Nijman R, Radmayr C, Stein R. Guidelines on Paediatric Urology, 2013.

55. Wang HH, Huang L, Routh JC, Nelson CP. Shock wave lithotripsy vs ureteroscopy: variation in surgical management of kidney stones at freestanding children's hospitals. J Urol 2012; 187: 1402-7.

56. Landau EH, Shenfeld OZ, Pode D, Shapiro A, Meretyk S, Katz G, Katz R, Duvdevani M, Hardak B, Cipele H, Hidas G, Yutkin V, Gofrit ON. Extracorporeal shock wave lithotripsy in prepubertal children: 22-year experience at a single institution with a single lithotriptor. J Urol 2009; 182(4 Suppl): $1835-9$

57. Muslumanoglu AY, Tefekli A, Sarilar O, Binbay M, Altunrende F, Ozkuvanci U. Extracorporeal shock wave lithotripsy as first line treatment alternative for urinary tract stones in children: a large scale retrospective analysis. J Urol 2003; 170: 24058.

58. Ather $\mathrm{MH}$, Noor MA. Does size and site matter for renal stones up to $30-\mathrm{mm}$ in size in children treated by extracorporeal lithotripsy? Urology 2003; 61: 212-215; discussion 215.

59. Raza A, Turna B, Smith G, Moussa S, Tolley DA. Paediatric urolithiasis: 15 years of local experience with minimally invasive endourological management of paediatric calculi. J Urol 2005; 174: 682-5

60. Rodrigues Netto N Jr, Longo JA, Ikonomidis JA, Rodrigues Netto M. Extracorporeal shock wave lithotripsy in children. J Urol 2002; 167: 2164-6.

61. Afshar K, McLorie G, Papanikolaou F, Malek R, Harvey E, Pippi-Salle JL, Bagli DJ, Khoury AE, Farhat W. Outcome of small residual stone fragments following shock wave lithotripsy in children. J Urol 2004; 172: 1600-3.

62. Tan AH, Al-Omar M, Watterson JD, Nott L, Denstedt JD, Razvi H. Results of shockwave lithotripsy for pediatric urolithiasis. J Endourol 2004; 18: 527-30.
63. Lottmann HB, Traxer O, Archambaud F, Mercier-Pageyral B. Monotherapy extracorporeal shock wave lithotripsy for the treatment of staghorn calculi in children. J Urol 2001; 165: 2324-7.

64. Ozgur Tan M, Karaoglan U, Sozen S, Bozkirli I. Extracorporeal shock-wave lithotripsy for treatment of ureteral calculi in paediatric patients. Pediatr Surg Int 2003; 19: 471-4.

65. Demirkesen O, Onal B, Tansu N, Altintaş R, Yalçin V, Oner A. Efficacy of extracorporeal shock wave lithotripsy for isolated lower caliceal stones in children compared with stones in other renal locations. Urology 2006; 67: 170-174; discussion 174-5.

66. Ozgur Tan M, Karaoglan U, Sen I, Deniz N, Bozkirli I. The impact of radiological anatomy in clearance of lower calyceal stones after shock wave lithotripsy in paediatric patients. Eur Urol 2003; 43: 188-93.

67. Onal B, Demirkesen O, Tansu N, Kalkan M, Altintaş R, Yalçin $V$. The impact of caliceal pelvic anatomy on stone clearance after shock wave lithotripsy for pediatric lower pole stones. J Urol 2004; 172: 1082-6.

68. Salerno A, Nappo SG, Matarazzo E, De Dominicis M, Caione $P$. Treatment of pediatric renal stones in a Western country: a changing pattern. J Pediatr Surg 2013; 48: 835-9.

69. Shokeir AA, El-Nahas AR, Shoma AM, Eraky I, El-Kenawy M, Mokhtar A, El-Kappany H. Percutaneous nephrolithotomy in treatment of large stones within horseshoe kidneys. Urology 2004; 64: 426-9.

70. Boormans JL, Scheepe JR, Verkoelen CF, Verhagen PC. Percutaneous nephrolithotomy for treating renal calculi in children. BJU Int 2005; 95: 631-4.

71. MS, Shokeir AA, Hafez AT, Shoma AM, El-Sherbiny MT, Mokhtar A, Eraky I, El-Kenawy M, El-Kappany HA. Percutaneous nephrolithotomy in children: early and late anatomical and functional results. J Urol 2004; 172: 107881.

72. Minevich E, Defoor W, Reddy P, Nishinaka K, Wacksman J, Sheldon C, Erhard M. Ureteroscopy is safe and effective in prepubertal children. J Urol 2005; 174: 276-9; discussion 279.

73. Soygur T, Zumrutbas AE, Gulpinar O, Suer E, Arikan N. Hydrodilation of the ureteral orifice in children renders ureteroscopic access possible without any further active dilation. J Urol 2006; 176: 285-7; discussion 287.

74. Dogan HS, Onal B, Satar N, Aygun C, Piskin M, Tanriverdi O, Gurocak S, Gunay LM, Burgu B, Ozden E, Nazli O, Erdem E, Yucel S, Kefi A, Demirci D, Uluocak N, Aridogan IA, Turunc T, Yalcin V, Kilinc M, Horasanli K, Tan MO, Soygur T, Sarikaya S, Kilicarslan H, Turna B, Doruk HE, Tekgul S. Factors affecting complication rates of ureteroscopic lithotripsy in children: results of multi-institutional retrospective analysis by Pediatric Stone Disease Study Group of Turkish Pediatric Urology Society. J Urol 2011; 186:1035-40.

75. Bozkurt OF, Resorlu B, Yildiz Y, Can CE, Unsal A. Retrograde intrarenal surgery versus percutaneous nephrolithotomy in the management of lower pole renal stones with diameter of 15 to $20 \mathrm{~mm}$. J Endourol 2011; 25: 1131-5.

76. Akman T, Binbay M, Ugurlu M, Kaba M, Akcay M, Yazici O, Ozgor F, Muslumanoglu AY. Outcomes of retrograde intrarenal surgery compared with percutaneous nephrolithotomy in elderly patients with moderate size kidney stones: a matched pair analysis. J Endourol 2012; 26: 625-9.

77. Lee RS, Passerotti CC, Cendron M, Estrada CR, Borer JG, Peters CA. Early results of robot assisted laparoscopic lithotomy in adolescents. J Urol 2007; 177: 2306-2309; discussion 2309-10. 